\title{
Dietary patterns, gender, and weight status among middle-aged and older adults in Taiwan: a cross-sectional study
}

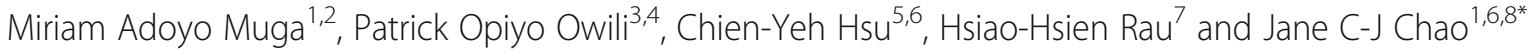

\begin{abstract}
Background: Diet has been associated with differences in weight and nutritional status of an individual. The prevalence of overweight and obesity increased among adults in Taiwan. Hence, we examined the relationship between dietary patterns and weight status by gender among middle-aged and older adults in Taiwan.

Methods: The cross-sectional data of 62,965 participants aged $\geq 40$ years were retrieved from the Mei Jau health screening institutions' database collected from 2001 and 2010. Diet information was evaluated using a food frequency questionnaire, while the dietary patterns were derived using principal component analysis before summing up and dividing into quintiles of consumption. The association between dietary patterns and weight status among adult men and women was explored using multinomial logistic regression models. Three models were analyzed before stratifying data by gender.

Results: Two dietary patterns were derived with one reflecting a high consumption of vegetables and fruits (vegetable-fruit dietary pattern) and the other a high consumption of meat and processed foods (meat-processed dietary pattern). After adjustment, highest consumption of vegetables and fruits (Q5) reduced the likelihood of being overweight $(\mathrm{OR}=0.91 ; 95 \% \mathrm{Cl}, 0.85-0.97)$ or obese $(\mathrm{OR}=0.85 ; 95 \% \mathrm{Cl}, 0.78-0.92)$, while highest consumption of meat and processed foods increased the likelihood of being overweight $(\mathrm{OR}=1.50 ; 95 \% \mathrm{Cl}, 1.40-1.59)$ or obese $(\mathrm{OR}=1.94 ; 95 \% \mathrm{Cl}, 1.79-2.10)$. Women were less likely to be overweight or obese with the highest intake of fruits and vegetables (Q5) while both genders were more likely to be overweight or obese with high consumption of meat and processed foods.

Conclusions: High intake of vegetables and fruits is associated with lower odds of being overweight or obese, especially among women. But, high intake of meat and processed foods is associated with higher odds of overweight and obesity in both genders.
\end{abstract}

Keywords: Dietary patterns, Body mass index, Underweight, Overweight, Obesity

\section{Background}

In the past two decades, the prevalence of overweight and obesity in Taiwan among adults has increased from $33 \%$ to $44 \%$, with the highest increase found among men (from 33\% to 51\%) than among women (from 33\% to 36\%) [1]. Being overweight or obese increases the risk of non-communicable diseases (NCDs) and some cancers

\footnotetext{
*Correspondence: chenjui@tmu.edu.tw

${ }^{1}$ School of Nutrition and Health Sciences, College of Nutrition, Taipei Medical University, Taipei, Taiwan

${ }^{6}$ Master Program in Global Health and Development, College of Public

Health, Taipei Medical University, Taipei, Taiwan

Full list of author information is available at the end of the article
}

such as endometrial, breast, and colon cancers [2]. Several factors such as dietary behavior, psychological factors, hereditary factors, and environmental factors have been linked to overweight and obesity, with diet being the most predominant factor leading to the imbalance between caloric intake and output [3]. Increases in the Western-style foods, refined foods, and high calorie foods, and a decrease in physical activity have been associated with weight changes $[4,5]$, and in recent years, dietary pattern in Taiwan has been characterized by a mixture of Chinese traditional diet and Western diet with an increased proportion of animal-based diet due 
to increased Western-style fast foods [6, 7]. To reduce the prevalence of obesity in Taiwan, it is important to consider changes in dietary behavior from a public health perspective and to promote the population wellbeing in general.

Authors using comprehensive analyses and factor analysis to derive dietary patterns in the Western population have also shown that plant-based dietary pattern and Western-style dietary pattern were negatively and positively associated with weight status, respectively [8]. Studies from Asian countries have also evidenced that diet is associated with weight changes [9-16], with most of these studies indicating a positive relationship between diet rich in meat and obesity $[12-14,16]$. However, there is still conflicting evidence, in regard to vegetable-rich diet. Some authors found that a diet rich in vegetables lowers the risk of obesity [9], while others found that vegetable-rich diet is positively associated with obesity [11, 17]; and yet, others found a no association $[13,16]$. These studies however were performed in different Asian countries. The previous cross-sectional study in Taiwan revealed that the vegetarians aged from 20 to 98 years had a lower risk of obesity compared with the matched non-vegetarians [18].

The increase in overweight and obese population in Taiwan may pose another challenge of NCDs, even if health promotion effort has been progressing in Taiwan, which may lead to more pressure on the current universal health care coverage system in Taiwan. Moreover, differences in diet cultures, food preparation methods, dietary environment, and anthropometric standards between the Eastern and Western countries add to the importance of a population-specific study on dietary patterns. Additionally, no studies have been reported on the association between dietary patterns and weight status by gender particularly among mid-aged and older adults in Taiwan. Therefore, the study investigated the association between dietary patterns and weight status among middle-aged and older adults in Taiwan. Furthermore, in order to extend the finding on obesity among Taiwanese adults [1], we explored whether the correlation between dietary patterns and weight status differed by gender.

\section{Methods}

\section{Data source and subjects}

The cross-sectional data of participants screened from 2001 to 2010 was acquired from a health screening institutions called Mei Jau (MJ) in Taiwan. The institutions collected detailed information on diet and weight status of adults at the point of entry during different time points across 10 year period. But, only data of all participants collected at the point of entry were used in our study. Following the rapid change in the weight status among adults in Taiwan [1], we only focused on adults who were 40 years and above from the dataset to explore our objectives. After eliminating those who had multiple entries, diabetes mellitus, renal disease, liver disorders, or any types of cancer, those taking lipidlowering medications and had psychiatric disorder, and missing data in any of the variables used in this study, a total of 62,965 subjects (men: 32,735, 52\%; women: $30,230,48 \%$ ) were used for our final analyses. The subjects with these diseases had usually been on the prescribed diet due to their health conditions. Data that had multiple entries of the subjects were excluded to avoid repeated measures from the same individual, while the first entry of the subjects with multiple entries was included consistently. If data collected over time from the same individual would have been included, it would have led to diagnostic suspicion bias and a reduction of a statistical power. We, therefore, used the baseline data (i.e. at the point of entry) of the participants in this study. However, it would be necessary for another study to assess the effect of a screening program on dietary changes and health outcome of the same participants.

\section{Ethical considerations}

Taipei Medical University-Joint Institutional Review Board (TMU-JIRB) approved the study. All the subjects signed a written informed consent that the data would be used for academic research purposes only without their personal identification information. Participation was voluntary.

\section{$\mathrm{BMI}$ and weight status}

Precision electronic weight scales were used to measure the body weight of the participants by the clinicians, while aluminum anthropometers were used for height measurements. Body weight and height of the participants were measured to calculate body mass index (BMI) as weight in kilograms divided by the square of height in meters. Weight status was defined using the Taiwan's Ministry of Health and Welfare criteria where underweight, normal weight, overweight, and obesity are defined as $\mathrm{BMI}<$ $18.5 \mathrm{~kg} / \mathrm{m}^{2}, 18.5 \mathrm{~kg} / \mathrm{m}^{2} \leq \mathrm{BMI}<24 \mathrm{~kg} / \mathrm{m}^{2} ; 24 \mathrm{~kg} / \mathrm{m}^{2} \leq$ $\mathrm{BMI}<27 \mathrm{~kg} / \mathrm{m}^{2}$; and BMI $\geq 27 \mathrm{~kg} / \mathrm{m}^{2}$, respectively [19].

\section{Dietary assessment and patterns}

The MJ Health Management Services developed, validated, and standardized a self-administered food frequency questionnaire (FFQ) that was used to assess participants' diet. During the process of validation and standardization, twenty two food groups were classified from eighty five closed-ended questions based on previous studies [20-22]. The servings and frequency (per day or per week) of dietary intake were evaluated using FFQ with twenty two food groups (indicated in Additional file 1: Table S1) according to the consumption of food items at 
mealtimes $[23,24]$ in the past one month before data collection. For example, the intake of vegetables and root crops was assessed using the number of bowls per day (i.e., a bowl equals $11 \mathrm{~cm}$ in diameter). The intake of fruits as well as rice and flour products was measured using servings per day, while the responses for other food items were measured using servings per week. Examples in FFQ were given on the definition of one serving of food.

Dietary patterns were then derived using principal component analysis (PCA). A factor loading $\geq 0.30$ was considered as the cut-off value to identify dietary patterns [25]. The food scores from 1 to 5 defined as the lowest to the highest frequency of intake in each dietary pattern were summed up before dividing into quintiles using xtile command in STATA software (StataCorp LP, College Station, Texas, USA).

\section{Other covariates}

The other covariates that were also collected using a questionnaire included demographic, lifestyle, and health characteristics. The demographic and lifestyle characteristics were: gender, age group (i.e., 40-44, 45-49, 50-54, 55-59, and $\geq 60$ ), education level (i.e., < high school, high school, and $>$ high school), marital status (i.e., married, widows/ divorced, and never married), smoking status $(0=$ no; $1=$ yes), drinking alcohol $(0=$ no; $1=$ yes $)$, and physical activity $(0=$ no; $1=$ yes $)$. The question regarding smoking was binary defined as yes if the participant smoked cigarettes irrespective of the frequency and no if otherwise, the same was also for drinking alcohol. Physical activity was also defined as yes if the respondent engaged in exercises for more than one hour in a week and no if otherwise. The three health characteristics were: whether the participant has cardiovascular disease (CVD) defined as any disease that involves the heart or blood vessels $(0=$ no; $1=$ yes), systolic blood pressure $(\mathrm{SBP})>120 \mathrm{mmHg}$ $(0=$ no; $1=$ yes $)$, and diastolic blood pressure $(\mathrm{DBP})>$ $80 \mathrm{mmHg}(0=$ no; $1=$ yes $)$. Participants who had been previously diagnosed with these health conditions, such as CVD, might have changed their lifestyle, and so the need to adjust for CVD indicator.

\section{Statistical analysis}

We performed all statistical analyses using STATA version 13.1 (StataCorp LP, College Station, Texas, USA). Frequencies of demographic, lifestyle, health characteristics, and dietary patterns were determined according to weight status and compared using a chi-square test. Multinomial logistic regression was employed to determine the relationship between dietary patterns and weight status. Dummy variables were created for each of the variables to compare with the reference group. The reference group for vegetable-fruit and meat-processed dietary patterns was quintile 1 (Q1) which is the lowest or no food consumption, while the normal weight (i.e., BMI between 18.5 and $23.9 \mathrm{~kg} / \mathrm{m}^{2}$ ) was the reference group for the weight status. Different models were derived. Model 1 was unadjusted while Model 2 was adjusted for age, education level, marital status, smoking, drinking, and physical activity; and Model 3 was adjusted for all the variables in Model 2 plus CVD, SBP, and DBP. Participants with prior diagnosis of CVD, SBP, and DBP may have had dietary modification in an effort to control these health characteristics, and hence controlling for the same was necessary. We finally stratified the analyses by gender to explore if gender is an effect modifier using the elaboration model. The $p$-value for trend of the dietary patterns was determined using the quintiles levels as a continuous indication. The alpha level of significance was $p<0.05$.

\section{Results}

\section{Dietary patterns}

Two uncorrelated dietary patterns were derived from the FFQ using PCA with orthogonal varimax rotation and retention of two factors [26, 27], and defined as vegetablefruit ( 9 foods or food groups) and meat-processed (12 foods or food groups) dietary patterns to reflect dietary consumption with high intake in vegetables and fruits or meats and processed foods, respectively (Additional file 1: Table S1). The food groups of legumes and soy products as well as seafood had a factor loading $\geq 0.30$ in both factors, and were classified as vegetable-fruit or meat-processed dietary pattern, respectively.

Vegetable-fruit dietary pattern was characterized by high consumption of fruits, light-colored vegetables, dark-colored vegetables, root crops, legumes/soy products, vegetables with added oil/fat, milk, dairy products, and whole grains, while meat-processed dietary pattern was characterized by high consumption of meats, deep-fried foods, preserved and processed foods, organ meats, seafood, soy sauce or other dips, fried (rice and flour) products, sugary drinks, instant noodles, eggs, bread, and jam/ honey. Only the food group of rice and flour products had a factor loading $<0.30$ in both factors, and was considered in neither vegetable-fruit nor meat-processed dietary pattern. Vegetable-fruit and meat-processed dietary patterns had a percentage of cumulative variance of $96.8 \%$ ( $46.4 \%$ and $50.4 \%$, respectively) and eigenvalues greater than 1.0. These two dietary patterns were comparable to the Western-like dietary patterns but varied from approaches that include nutrients [26, 28, 29]. The theoretical maximum scores if a person consumed the entire vegetable-fruit dietary pattern (i.e., 9 food groups) and meat-processed dietary pattern (i.e., 12 food groups) were 45 and 60, respectively. However, the total score for vegetable-fruit dietary pattern was 42 (range, 9-42) while 
for meat-processed dietary pattern was 56 (range, 11-56). Table 1 shows the range of each quintile.

\section{Characteristics of participants}

The characteristics of respondents were stratified across different weight status, and it showed that less than 20\% of all the participants were in the highest quintile (Q5) of vegetable-fruit (15.2\%) or meat-processed dietary pattern (15.1\%) (Table 1). More than half of the respondents in the overweight group (62.7\%) and obese group (56.4\%) were males. In overall, majority of the total participants had high school education level or above (73.7\%), were married $(86.3 \%)$, were non-smokers $(80.4 \%)$, were nondrinkers (81.4\%), and had non-sedentary lifestyle (63.9\%). On the other hand, only $4.3 \%$ of the respondents had been previously diagnosed with CVD, while $50.4 \%$ and $26.1 \%$ of the respondents had high SBP $(>120 \mathrm{mmHg})$ and high DBP (> $80 \mathrm{mmHg}$ ), respectively. More than a half of the

Table 1 Characteristics of the participants aged $\geq 40$ years by weight status in Taiwan

\begin{tabular}{|c|c|c|c|c|c|c|}
\hline & & Weight status, & & & & \\
\hline & All, \% & Underweight & Normal weight & Overweight & Obese & $p^{a}$ \\
\hline$n$ & 62,965 & 2073 & 32,907 & 18,820 & 9165 & - \\
\hline Vegetable-fruit pattern & & & & & & $<0.001$ \\
\hline Q1 (range, 9-14) & 21.9 & 24.4 & 20.8 & 22.1 & 25.0 & \\
\hline Q2 (range, 15-16) & 20.9 & 20.7 & 20.8 & 20.8 & 21.3 & \\
\hline Q3 (range, 17-18) & 21.0 & 20.8 & 20.8 & 21.6 & 19.1 & \\
\hline Q4 (range, 19-21) & 21.0 & 19.0 & 21.9 & 20.6 & 19.1 & \\
\hline Q5 (range, 22-42) & 15.2 & 15.1 & 15.7 & 14.9 & 14.1 & \\
\hline Meat-processed pattern & & & & & & $<0.001$ \\
\hline Q1 (range, 11-17) & 21.3 & 24.8 & 22.3 & 19.9 & 19.8 & \\
\hline Q2 (range, 18-19) & 18.4 & 19.3 & 19.5 & 17.5 & 16.8 & \\
\hline Q3 (range, 20-22) & 26.6 & 27.0 & 26.8 & 26.6 & 25.7 & \\
\hline Q4 (range, 23-25) & 18.5 & 16.2 & 18.0 & 19.4 & 18.9 & \\
\hline Q5 (range, 26-56) & 15.1 & 12.9 & 13.4 & 16.5 & 18.8 & \\
\hline Gender, \% male & 52.0 & 34.7 & 45.7 & 62.7 & 56.4 & $<0.001$ \\
\hline Age, years & & & & & & $<0.001$ \\
\hline $40-44$ & 28.8 & 40.5 & 32.0 & 24.4 & 23.0 & \\
\hline $45-49$ & 20.9 & 19.3 & 21.8 & 20.6 & 18.6 & \\
\hline $50-54$ & 15.8 & 10.2 & 15.0 & 16.9 & 17.9 & \\
\hline $55-59$ & 11.4 & 7.6 & 10.3 & 12.7 & 13.7 & \\
\hline$\geq 60$ & 23.1 & 22.4 & 20.9 & 25.4 & 26.8 & \\
\hline Education level & & & & & & $<0.001$ \\
\hline$<$ High School & 26.3 & 19.5 & 22.3 & 28.6 & 37.4 & \\
\hline High school & 31.9 & 32.0 & 33.2 & 31.1 & 28.8 & \\
\hline$>$ High school & 41.8 & 48.5 & 44.5 & 40.3 & 33.7 & \\
\hline Marital status & & & & & & $<0.001$ \\
\hline Married & 86.3 & 80.7 & 85.9 & 87.8 & 85.8 & \\
\hline Widows/divorced & 10.9 & 11.9 & 10.8 & 10.5 & 11.9 & \\
\hline Never married & 2.8 & 7.4 & 3.4 & 1.7 & 2.3 & \\
\hline Smoking, current & 19.6 & 19.1 & 17.8 & 22.1 & 20.8 & $<0.001$ \\
\hline Drinking, current & 18.6 & 11.7 & 16.6 & 22.2 & 20.4 & $<0.001$ \\
\hline Physical activity, yes & 63.9 & 55.9 & 64.6 & 65.8 & 59.7 & $<0.001$ \\
\hline CVD & 4.3 & 4.3 & 3.5 & 4.8 & 6.2 & $<0.001$ \\
\hline $\mathrm{SBP},>120 \mathrm{mmHg}$ & 50.4 & 30.1 & 41.9 & 58.0 & 69.5 & $<0.001$ \\
\hline $\mathrm{DBP}_{1}>80 \mathrm{mmHg}$ & 26.1 & 9.4 & 19.5 & 31.7 & 42.0 & $<0.001$ \\
\hline
\end{tabular}

${ }^{\mathrm{a}} \mathrm{X}^{2}$ test for difference. $C V D$ cardiovascular disease, SBP systolic blood pressure, DBP diastolic blood pressure 
Table 2 Crude odds ratios of dietary patterns and characteristics by weight status of the participants aged $\geq 40$ years in Taiwan, $n=62,965$

\begin{tabular}{|c|c|c|c|}
\hline & \multicolumn{3}{|c|}{ Model 1, Odds ratio (95\% confidence interval) } \\
\hline & $\begin{array}{l}\text { Underweight } \\
n=2073\end{array}$ & $\begin{array}{l}\text { Overweight } \\
n=18,820\end{array}$ & $\begin{array}{l}\text { Obese } \\
n=9165\end{array}$ \\
\hline \multicolumn{4}{|l|}{ Vegetable-fruit pattern } \\
\hline Q1 & 1 & 1 & 1 \\
\hline Q2 & $0.85(0.74,0.97)^{*}$ & $0.94(0.89,0.99)^{*}$ & $0.85(0.80,0.99)^{* * *}$ \\
\hline Q3 & $0.86(0.75,0.98)^{*}$ & $0.97(0.92,1.03)$ & $0.82(0.76,0.88)^{* * *}$ \\
\hline Q4 & $0.74(0.65,0.85)^{* * *}$ & $0.89(0.84,0.94)^{* * *}$ & $0.73(0.68,0.78)^{* * *}$ \\
\hline Q5 & $0.82(0.71,0.95)^{* *}$ & $0.89(0.84,0.95)^{* * *}$ & $0.75(0.69,0.81)^{* * *}$ \\
\hline$P$-trend & $<0.001$ & $<0.001$ & $<0.001$ \\
\hline \multicolumn{4}{|c|}{ Meat-processed pattern } \\
\hline Q1 & 1 & 1 & 1 \\
\hline Q2 & $0.89(0.78,1.02)$ & $0.99(0.94,1.06)$ & $0.97(0.90,1.05)$ \\
\hline Q3 & $0.90(0.80,1.02)$ & $1.11(1.05,1.16)^{* * *}$ & $1.08(1.00,1.15)^{*}$ \\
\hline Q4 & $0.81(0.70,0.93)^{* *}$ & $1.20(1.13,1.27)^{* * *}$ & $1.18(1.09,1.27)^{* * *}$ \\
\hline Q5 & $0.87(0.74,1.01)$ & $1.38(1.30,1.47)^{* * *}$ & $1.57(1.46,1.70)^{* * *}$ \\
\hline$P$-trend & 0.012 & $<0.001$ & $<0.001$ \\
\hline \multicolumn{4}{|l|}{ Gender } \\
\hline Female & 1 & 1 & 1 \\
\hline Male & $0.63(0.58,0.69)^{* * *}$ & $2.00(1.93,2.07)^{* * *}$ & $1.53(1.46,1.61)^{* * *}$ \\
\hline \multicolumn{4}{|l|}{ Age, years } \\
\hline $40-44$ & 1 & 1 & 1 \\
\hline $45-49$ & $0.70(0.62,0.78)^{* * *}$ & $1.24(1.18,1.31)^{* * *}$ & $1.19(1.11,1.28)^{* * *}$ \\
\hline $50-54$ & $0.53(0.46,0.63)^{* * *}$ & $1.48(1.40,1.57)^{* * *}$ & $1.67(1.55,1.79)^{* * *}$ \\
\hline $55-59$ & $0.58(0.49,0.69)^{* * *}$ & $1.61(1.51,1.72)^{* * *}$ & $1.85(1.71,2.01)^{* * *}$ \\
\hline$\geq 60$ & $0.84(0.75,0.95)^{* *}$ & $1.59(1.51,1.68)^{* * *}$ & $1.78(1.67,1.91)^{* * *}$ \\
\hline \multicolumn{4}{|l|}{ Education level } \\
\hline$<$ High School & 1 & 1 & 1 \\
\hline High school & $1.10(0.97,1.25)$ & $0.73(0.70,0.77)^{* * *}$ & $0.52(0.49,0.55)^{* * *}$ \\
\hline > High school & $1.25(1.11,1.41)^{* * *}$ & $0.71(0.67,0.74)^{* * *}$ & $0.45(0.43,0.48)^{* * *}$ \\
\hline \multicolumn{4}{|l|}{ Marital status } \\
\hline Married & 1 & 1 & 1 \\
\hline Widows/divorced & $1.17(1.02,1.35)^{*}$ & $0.95(0.90,1.01)$ & $1.11(1.03,1.19)^{* *}$ \\
\hline Never married & $2.35(1.97,2.80)^{* * *}$ & $0.51(0.45,0.57)^{* * *}$ & $0.67(0.58,0.78)^{* * *}$ \\
\hline \multicolumn{4}{|l|}{ Smoking, current } \\
\hline No & 1 & 1 & 1 \\
\hline Yes & $1.08(0.97,1.22)$ & $1.31(1.25,1.37)^{* * *}$ & $1.21(1.14,1.28)^{* * *}$ \\
\hline \multicolumn{4}{|l|}{ Drinking, current } \\
\hline No & 1 & 1 & 1 \\
\hline Yes & $0.67(0.58,0.76)^{* * *}$ & $1.43(1.37,1.50)^{* * *}$ & $1.29(1.22,1.37)^{* * *}$ \\
\hline \multicolumn{4}{|l|}{ Physical activity } \\
\hline No & 1 & 1 & 1 \\
\hline Yes & $0.70(0.64,0.76)^{* * *}$ & $1.05(1.02,1.09)^{* *}$ & $0.81(0.78,0.85)^{* * *}$ \\
\hline \multicolumn{4}{|l|}{ CVD } \\
\hline No & 1 & 1 & 1 \\
\hline
\end{tabular}


Table 2 Crude odds ratios of dietary patterns and characteristics by weight status of the participants aged $\geq 40$ years in Taiwan, $n=62,965$ (Continued)

\begin{tabular}{|c|c|c|c|}
\hline & \multicolumn{3}{|c|}{ Model 1, Odds ratio (95\% confidence interval) } \\
\hline & $\begin{array}{l}\text { Underweight } \\
n=2073\end{array}$ & $\begin{array}{l}\text { Overweight } \\
n=18,820\end{array}$ & $\begin{array}{l}\text { Obese } \\
n=9165\end{array}$ \\
\hline Yes & $1.24(1.00,1.55)$ & $1.42(1.30,1.55)^{* * *}$ & $1.84(1.66,2.05)^{* * *}$ \\
\hline \multicolumn{4}{|c|}{$\mathrm{SBP},>120 \mathrm{mmHg}$} \\
\hline No & 1 & 1 & 1 \\
\hline Yes & $0.60(0.54,0.66)^{* * *}$ & $1.92(1.85,1.99)^{* * *}$ & $3.16(3.00,3.32)^{* * *}$ \\
\hline \multicolumn{4}{|c|}{$\mathrm{DBP}_{1}>80 \mathrm{mmHg}$} \\
\hline No & 1 & 1 & 1 \\
\hline Yes & $0.43(0.37,0.50)^{* * *}$ & $1.92(1.84,2.00)^{* * *}$ & $2.99(2.84,3.15)^{* * *}$ \\
\hline
\end{tabular}

respondents in the overweight group (58.0\%) and obese group $(69.5 \%)$ had high SBP (> $120 \mathrm{mmHg})$. The chisquare test indicated a statistical difference in all the variables for the characteristics of the subjects at $p<0.001$.

\section{Association between dietary patterns and weight status}

The crude odds ratios of dietary patterns and other factors associated with weight status among middle-aged adults in Taiwan are shown in Table 2. The results showed those who had more intake of vegetable-fruit diet (Q2-Q5) were less likely to be underweight, overweight, or obese with exception of Q2 that was not statistically significant in the overweight group. However, those who consumed higher quantity of meat and processed foods (Q2-Q5) were more likely to be overweight or obese. In addition, men were more likely to be overweight $(\mathrm{OR}=2.0,95 \% \mathrm{CI}=1.93-2.07)$ or obese $(\mathrm{OR}=$ 1.53, 95\% CI $=1.46-1.70)$ than women, and the odds ratio of being overweight or obese also increased with age. Moreover, the participants who had higher education level were less likely to be overweight or obese than those who had not attained high school graduation. Individuals with a higher education were more likely to be underweight $(\mathrm{OR}=1.25 ; 95 \% \mathrm{CI}, 1.11-1.41)$ and less likely to be overweight ( $\mathrm{OR}=0.71 ; 95 \% \mathrm{CI}, 0.67-0.74$ ) or obese $(\mathrm{OR}=0.45 ; 95 \% \mathrm{CI}, 0.43-0.48)$. Those who were smoking, drinking alcohol, had CVD, SBP $>120 \mathrm{mmHg}$, or DBP $>80 \mathrm{mmHg}$ were also more likely to be overweight or obese. Physically active participants were not only less likely to be obese ( $\mathrm{OR}=0.81,95 \% \mathrm{CI}=0.78-0.85)$ or underweight $(\mathrm{OR}=0.70 ; 95 \% \mathrm{CI}, 0.64-0.76)$, but were also more likely to be overweight $(\mathrm{OR}=1.05 ; 95 \% \mathrm{CI}, 1.02-1.09)$.

After adjusting for demographic and lifestyle characteristics (Model 2) in Table 3, adults who were consuming more vegetables and fruits (Q5) were less likely to be overweight $(\mathrm{OR}=0.91 ; 95 \% \mathrm{CI}, 0.85-0.97)$ or obese $(\mathrm{OR}=0.85 ; 95 \% \mathrm{CI}, 0.78-0.92)$ while adults who were consuming more meat (Q5) were more likely to be overweight $(\mathrm{OR}=1.50 ; 95 \% \mathrm{CI}, 1.40-1.59)$ or obese $(\mathrm{OR}=1.94 ; 95 \% \mathrm{CI}, 1.79-2.10)$. Model 3 remained statistically significant with adjustment of health characteristics. Adults who had the highest consumption of vegetables-fruit dietary pattern (Q5) were still less likely to be overweight $(\mathrm{OR}=0.92 ; 95 \% \mathrm{CI}, 0.86-0.98)$ or obese ( $\mathrm{OR}=0.87 ; 95 \% \mathrm{CI}, 0.80-0.94)$, while the ORs of the highest intake of meat and processed foods (Q5) indicated the likelihood of being overweight ( $\mathrm{OR}=1.48$; 95\% CI, 1.39-1.58) or obese (OR $=1.92$; 95\% CI, 1.77-2.08). There is somewhat a dose-response relationship, that is, with the increase in the quintile of consumption in the meat and processed foods pattern, the likelihood of being overweight and obese increased, while the vegetables-fruit dietary pattern exhibited a negative association with the increase in quintiles of consumption.

In the stratified analysis by gender in Table 4, the relationship between dietary patterns and weight status suggested that only women who consumed a diet rich in vegetables and fruits (Q5) were less likely to be overweight $(\mathrm{OR}=0.86$; $95 \% \mathrm{CI}, 0.78-0.95)$ or obese $(\mathrm{OR}=$ 0.82 ; 95\% CI, 0.72-0.93); though, $\mathrm{Q} 4$ and the trend $p$ value $(p=0.002)$ for men were statistically significant. On the other hand, those who consumed a diet high in meat and processed foods (Q3 to Q5) were more likely to be either overweight or obese both among men and women; also, the odds of being underweight were low in both men $(\mathrm{Q} 2$ to $\mathrm{Q} 4, \mathrm{OR}=0.69-0.78)$ and women $(\mathrm{Q} 4$, $\mathrm{OR}=0.81$ ) who consumed meat and processed foods. In general, our results indicated a somewhat dose-response relationship between dietary intake and weight change.

\section{Discussion}

Our study examined the relationship between dietary patterns and weight status among middle-aged and elderly men and women in Taiwan. We found that men and women who consumed a diet high in meat and processed foods were more likely to be overweight or 
Table 3 Adjusted odds ratios (95\% confidence interval) of the multinomial logistic regression of weight status among the participants aged $\geq 40$ years in Taiwan, $n=62,965$

\begin{tabular}{|c|c|c|c|}
\hline & \multicolumn{3}{|c|}{ Men and women, Odds ratio ( $95 \%$ confidence interval) } \\
\hline & $\begin{array}{l}\text { Underweight } \\
n=2073\end{array}$ & $\begin{array}{l}\text { Overweight } \\
n=18,820\end{array}$ & $\begin{array}{l}\text { Obese } \\
n=9165\end{array}$ \\
\hline \multicolumn{4}{|l|}{ Model 2} \\
\hline \multicolumn{4}{|c|}{ Vegetable-fruit pattern } \\
\hline Q1 & 1 & 1 & 1 \\
\hline Q2 & $0.89(0.78,1.02)$ & $0.96(0.91,1.02)$ & $0.92(0.85,0.98)^{*}$ \\
\hline Q3 & $0.92(0.80,1.05)$ & $1.00(0.95,1.06)$ & $0.91(0.85,0.98)^{* *}$ \\
\hline Q4 & $0.80(0.70,0.92)^{* *}$ & $0.92(0.87,0.97)^{* *}$ & $0.82(0.77,0.89)^{* * *}$ \\
\hline Q5 & $0.92(0.79,1.07)$ & $0.91(0.85,0.97)^{* *}$ & $0.85(0.78,0.92)^{* * *}$ \\
\hline$P$-trend & 0.059 & $<0.001$ & $<0.001$ \\
\hline \multicolumn{4}{|c|}{ Meat-processed pattern } \\
\hline Q1 & 1 & 1 & 1 \\
\hline Q2 & $0.88(0.77,1.01)$ & $1.04(0.98,1.10)$ & $1.08(1.00,1.16)$ \\
\hline Q3 & $0.88(0.77,1.00)^{*}$ & $1.18(1.11,1.24)^{* * *}$ & $1.25(1.16,1.34)^{* * *}$ \\
\hline Q4 & $0.78(0.67,0.90)^{* * *}$ & $1.29(1.22,1.37)^{* * *}$ & $1.42(1.31,1.53)^{* * *}$ \\
\hline Q5 & $0.81(0.69,0.95)^{* *}$ & $1.50(1.40,1.59)^{* * *}$ & $1.94(1.79,2.10)^{* * *}$ \\
\hline$P$-trend & $<0.001$ & $<0.001$ & $<0.001$ \\
\hline \multicolumn{4}{|l|}{ Model 3} \\
\hline \multicolumn{4}{|c|}{ Vegetable-fruit pattern } \\
\hline Q1 & 1 & 1 & 1 \\
\hline Q2 & $0.89(0.78,1.02)$ & $0.97(0.92,1.03)$ & $0.93(0.86,1.00)^{*}$ \\
\hline Q3 & $0.91(0.80,1.05)$ & $1.01(0.95,1.07)$ & $0.92(0.85,0.99)^{*}$ \\
\hline Q4 & $0.80(0.69,0.92)^{* *}$ & $0.93(0.88,0.98)^{*}$ & $0.84(0.78,0.91)^{* * *}$ \\
\hline Q5 & $0.92(0.79,1.07)$ & $0.92(0.86,0.98)^{* *}$ & $0.87(0.80,0.94)^{* * *}$ \\
\hline$P$-trend & 0.050 & 0.003 & $<0.001$ \\
\hline \multicolumn{4}{|c|}{ Meat-processed pattern } \\
\hline Q1 & 1 & 1 & 1 \\
\hline Q2 & $0.88(0.77,1.01)$ & $1.04(0.98,1.11)$ & $1.08(1.00,1.17)^{*}$ \\
\hline Q3 & $0.88(0.77,1.00)^{*}$ & $1.18(1.12,1.24)^{* * *}$ & $1.25(1.17,1.35)^{* * *}$ \\
\hline Q4 & $0.78(0.67,0.90)^{* * *}$ & $1.29(1.22,1.37)^{* * *}$ & $1.41(1.31,1.53)^{* * *}$ \\
\hline Q5 & $0.82(0.70,0.96)^{*}$ & $1.48(1.39,1.58)^{* * *}$ & $1.92(1.77,2.08)^{* * *}$ \\
\hline$P$-trend & 0.002 & $<0.001$ & $<0.001$ \\
\hline
\end{tabular}

Normal weight is the reference group $(n=32,907)$; model 2 is adjusted for age, education level, marital status, smoking, drinking, and physical activity; model 3 is adjusted for model 2 plus cardiovascular disease, systolic blood pressure, and diastolic blood pressure. Values with the star sign are significantly different from the reference group (indicated with an odds ratio of 1). ${ }^{*} p<0.05,{ }^{* *} p<0.01,{ }^{* * *} p<0.001$

obese, unlike those who consumed a diet rich in vegetables and fruits. The prevalence of overweight and obesity from the year 1993 to 1996 increased in Taiwan from $33.4 \%$ to $51.0 \%$ in adult men and slightly in adult women from $33.5 \%$ to $35.9 \%$ [1]; and with these weight changes, in both men and women, dietary habits may have contributed to the increase in the prevalence of overweight and obesity. Previous studies also suggested that the change in lifestyle as well as in eating habit, from Chinese traditional dietary pattern to Western dietary pattern, could explain these relationships [30, 31]. According to the current methods of classifying dietary patterns in the Western countries, the vegetable-fruit dietary pattern could be referred to as 'prudent and healthy' dietary pattern [4].

In our study, the association between meat-processed foods dietary pattern and weight status did not attenuate among both men and women who were overweight or obese after adjusting for all the potential confounders. The evidence suggests that diet is a key factor of weight status and chronic disease like CVD [9, 32, 33]. Our finding also suggested that high intake of meat and processed foods by both men and women increased the chances of being overweight or obese.

In contrast to the previous studies which found that a diet high in vegetables was positively related with weight gain and obesity in China [11, 17], our results showed that adults who consumed a vegetable-rich diet were less likely to be overweight or obese. These differences may have been as a result of sedentary lifestyle, oily stir-fried vegetables, or even a change in dietary behavior in China, where those who are overweight or obese may have been advised to change eating habits, and were probably consuming a diet high in vegetables at the time the studies were conducted. More studies that would confirm this hypothesis are therefore necessary.

On the other hand, we found that high consumption of meat and processed foods increased the possibility of being overweight or obese. This supports the results of previous studies that diet rich in meat is associated with change in body weight among Asian adults of Chinese or Korean descent $[12-14,16]$. The association between the meat-processed dietary pattern and weight status may be attributed to the mechanism of weight change with consumption of red meat and sugary foods as seen in this pattern. Studies have found that red meat is an energy-dense food containing saturated fat and cholesterol which may contribute to a surplus intake of energy, and hence increases the risk of overweight and obesity [34]. Additionally, high consumption of meat and processed foods may reveal some unnoticed dietary behavior or lifestyle which may have contributed to the weight differences as seen in this study. Typically, the traditional Chinese diet consists of plenty vegetables and low or moderate amounts of meat. But, with the increase in Western-style fast food outlet chains in Taiwan [6], it may have led to a change in dietary behavior from a more traditional Chinese diet to a Western-style diet that has more meat intake and less vegetable. Studies are therefore necessary to confirm this hypothesis. Even though it is frequently assumed that the primary reason of obesity is overeating combined with low physical activity, studies have shown that components of a diet may 
Table 4 Multinomial logistic regression of weight status among the participants aged $\geq 40$ years in Taiwan, stratified by gender, $n=62,965$

\begin{tabular}{|c|c|c|c|}
\hline & \multicolumn{3}{|c|}{ Stratified analysis by gender, Odds Ratio (95\% confidence interval) ${ }^{a}$} \\
\hline & $\begin{array}{l}\text { Underweight } \\
n=2073\end{array}$ & $\begin{array}{l}\text { Overweight } \\
n=18,820\end{array}$ & $\begin{array}{l}\text { Obese } \\
n=9165\end{array}$ \\
\hline \multicolumn{4}{|c|}{ Women, $n=30,230$} \\
\hline \multicolumn{4}{|c|}{ Vegetable-fruit pattern } \\
\hline Q1 & 1 & 1 & 1 \\
\hline Q2 & $0.88(0.74,1.05)$ & $0.92(0.84,1.01)$ & $0.86(0.77,0.96)^{* *}$ \\
\hline Q3 & $0.94(0.89,1.12)$ & $0.99(0.90,0.07)$ & $0.89(0.79,0.99)^{*}$ \\
\hline Q4 & $0.84(0.71,1.00)^{*}$ & $0.86(0.79,0.94)^{* *}$ & $0.81(0.72,0.90)^{* * *}$ \\
\hline Q5 & $0.99(0.81,1.18)$ & $0.86(0.78,0.95)^{* *}$ & $0.82(0.72,0.93)^{* * *}$ \\
\hline$P$-trend & 0.545 & $<0.001$ & $<0.001$ \\
\hline \multicolumn{4}{|c|}{ Meat-processed pattern } \\
\hline Q1 & 1 & 1 & 1 \\
\hline Q2 & $0.97(0.82,1.15)$ & $1.08(0.99,1.17)$ & $1.10(0.98,1.22)$ \\
\hline Q3 & $0.95(0.82,1.12)$ & $1.17(1.08,1.27)^{* * *}$ & $1.36(1.23,1.50)^{* * *}$ \\
\hline Q4 & $0.81(0.67,0.97)^{*}$ & $1.28(1.16,1.40)^{* * *}$ & $1.34(1.19,1.51)^{* * *}$ \\
\hline Q5 & $0.82(0.67,1.02)$ & $1.41(1.27,1.57)^{* * *}$ & $1.84(1.62,2.09)^{* * *}$ \\
\hline$P$-trend & 0.016 & $<0.001$ & $<0.001$ \\
\hline \multicolumn{4}{|c|}{ Men, $n=32,735$} \\
\hline \multicolumn{4}{|c|}{ Vegetable-fruit pattern } \\
\hline Q1 & 1 & 1 & 1 \\
\hline Q2 & $0.88(0.71,1.10)$ & $1.00(0.94,1.09)$ & $0.97(0.88,1.07)$ \\
\hline Q3 & $0.87(0.70,1.09)$ & $1.01(0.94,1.09)$ & $0.92(0.83,1.01)$ \\
\hline Q4 & $0.74(0.58,0.93)^{*}$ & $0.96(0.89,1.04)$ & $0.85(0.76,0.93)^{* * *}$ \\
\hline Q5 & $0.76(0.58,0.99)^{*}$ & $0.97(0.90,1.06)$ & $0.92(0.81,1.01)$ \\
\hline$P$-trend & 0.010 & 0.219 & 0.002 \\
\hline \multicolumn{4}{|c|}{ Meat-processed pattern } \\
\hline Q1 & 1 & 1 & 1 \\
\hline Q2 & $0.69(0.54,0.89)^{* *}$ & $1.02(0.94,1.11)$ & $1.12(1.00,1.26)^{*}$ \\
\hline Q3 & $0.76(0.61,0.94)^{*}$ & $1.14(1.06,1.23)^{* * *}$ & $1.19(1.07,1.32)^{* *}$ \\
\hline Q4 & $0.78(0.62,0.99)^{*}$ & $1.19(1.09,1.29)^{* * *}$ & $1.39(1.24,1.55)^{* * *}$ \\
\hline Q5 & $0.88(0.68,1.12)$ & $1.34(1.23,1.46)^{* * *}$ & $1.80(1.61,2.01)^{* * *}$ \\
\hline$P$-trend & 0.447 & $<0.001$ & $<0.001$ \\
\hline
\end{tabular}

${ }^{a}$ Adjusted for age, education level, marital status, smoking, drinking, physical activity, cardiovascular disease, systolic blood pressure, and diastolic blood pressure. Normal weight is the reference group $(n=32,907)$. Values with the star sign are significantly different from the reference group (indicated with an odds ratio of 1).* $p<0.05, * * 0<0.01, * * * 00001$

promote obesity even without excess energy consumption [35-37]. In general, our study highlighted the significance of meat and processed foods in increasing the prevalence of overweight and obesity among Taiwanese adults.

Our results also found that there was gender differences in weight status with women who consumed more vegetable and fruits (Q5) being less likely to be overweight or obese, and this was not the same for men at the same quintile level of consumption (Table 4). However, high consumption of meat and processed foods increased the likelihood of being overweight or obese in both genders.

\section{Strengths and limitations}

Several strengths and limitations in the interpretation of our data must be considered. Some strengths included a large sample size and the use of a standardized validated questionnaire may have produced a consistent result of a more representative population in Taiwan. Secondly, to the best of our knowledge, our study is the first in Taiwan to examine the association between dietary patterns and weight status among a middle-aged and elderly population. Thirdly, the potential known confounders were controlled for, and this increased internal reliability. Finally, the criteria of defining weight status in 
Taiwan are different from the recommended World Health Organization-Asian criteria which define a normal weight range as $18.5-24.9 \mathrm{~kg} / \mathrm{m}^{2}$, being overweight as $\geq 25 \mathrm{~kg} / \mathrm{m}^{2}$, and being obese as $\geq 30 \mathrm{~kg} / \mathrm{m}^{2}$ [38]. The difference in the cut-off criteria between Taiwan and Western countries shows that the problems and management of obesity may still be contentious, and hence more obesity-related studies with nationally derived criteria among different populations are still necessary. In this study, the nationally derived cut-off points are appropriate because of the difference in body structure between Asians and Caucasians. However, some of the limitations included the cross-sectional study design, of which, we are unable to establish causality between dietary patterns and weight status. A prospective cohort study would be more appropriate to explain and extend the finding of our study. Secondly, the multiple entries of the same individual were excluded in this study, and we could not monitor their dietary changes over time. Thirdly, the FFQ may not have been detailed enough to characterize the change in dietary behavior over time among Taiwanese, especially when the diet information of the past one month was collected as a snapshot and hence subjecting the data to a recall bias. Moreover, by using the food frequency data that were divided into quintiles of consumption, to indicate low and high consumption, it may also lead to misclassification bias where individuals who consuming vegetables and fruits more frequently are not certainly healthier compared with who with moderate frequency and vice versa. The recall bias also applies to self-reported measure of physical activity. Fourthly, we were unable to control for other important potential confounders, such as actual amount of energy and fat intake and household income among other potential confounders, due to data limitations. Finally, our subjects were confined to the middleaged population in one health management institution in Taiwan, and hence our findings may not be generalized to the entire population of Taiwan. A population based study is necessary to extend the finding of our study. Therefore, our results must be interpreted with caution.

\section{Conclusions}

In conclusion, our finding suggested that intake of a diet high in vegetables and fruits was strongly associated with lower odds ratios of overweight and obesity in women than in men, but a diet high in meat and processed foods was related with higher odds of overweight and obesity in both genders. However, the odds ratios were slightly higher in women consuming more meat and processed foods than those in men consuming the same diet. Future investigation could include longitudinal studies of obesity to determine the changes in dietary behavior over time and its effect on body weight in adulthood as well as the mechanism by which foods or active components of foods affect body weight. Despite the cross-sectional associations seen in our study, they may still have important for public health implications. Our findings support the current national Taiwan report indicating an increase in the prevalence of obesity. Public health promotion on changing dietary behavior is appropriate towards eating more vegetables, fruits, and whole grain and limiting high intake of meat and sugary foods in order to maintain healthy body weight in adulthood, mainly essential for men.

\section{Additional file}

Additional file 1: Table S1. Factor loadings of 22 foods or food groups. (DOCX 16 kb)

\section{Abbreviations}

BMI: body mass index; CVD: cardiovascular disease; DBP: diastolic blood pressure; FFQ: food frequency questionnaire; NCDs: non-communicable diseases; PCA: principal component analysis; SBP: systolic blood pressure; TMU-JIRB: Taipei Medical University-Joint Institutional Review Board

\section{Funding}

This research was not funded by any organizations.

\section{Availability of data and materials}

The data that support the findings of this study are available from Mei Jau (MJ) Health Management Institution but restrictions apply to the availability of these data, which were used under license for the current study, and so are not publicly available. Data are however available from the authors upon reasonable request and with permission of MJ Health Management Institution.

\section{Authors' contributions}

MAM and POO designed research; MAM, POO, and JCJC conducted the research; $\mathrm{CYH}$ and HHR managed dataset and retrieved data; POO, MAM, JCJC, $\mathrm{CYH}$, and HHR were responsible for data analysis and interpretation; MAM and POO wrote the paper; MAM, POO, JCJC, CYH, and HHR had primary responsibility for final content. All authors read and approved the final manuscript.

\section{Ethics approval and consent to participate}

The study was approved by the Taipei Medical University-Joint Institutional Review Board (TMU-JIRB). All the subjects signed a written informed consent that the data would be used without personal identification information for academic research purposes only. The ethics ID number of this research project is TMU-JIRB no. 201503016.

Competing interests

The authors declare that they have no competing interests.

\section{Publisher's Note}

Springer Nature remains neutral with regard to jurisdictional claims in published maps and institutional affiliations.

\section{Author details}

${ }^{1}$ School of Nutrition and Health Sciences, College of Nutrition, Taipei Medical University, Taipei, Taiwan. ${ }^{2}$ Department of Nutrition and Dietetics, University of Eastern Africa, Baraton, Eldoret, Kenya. ${ }^{3}$ Department of Public Health, School of Health Sciences, University of Eastern Africa, Baraton, Eldoret, Kenya. Institute of Environmental and Occupational Health Sciences, School of Medicine, National Yang-Ming University, Taipei, Taiwan. ${ }^{5}$ Department of Information Management, National Taipei University of Nursing and Health Sciences, Taipei, Taiwan. ${ }^{6}$ Master Program in Global Health and

Development, College of Public Health, Taipei Medical University, Taipei, 
Taiwan. ${ }^{7}$ Graduate Institute of Biomedical Informatics, College of Medical Technology, Taipei Medical University, Taipei, Taiwan. ${ }^{8}$ Nutrition Research Center, Taipei Medical University Hospital, Taipei, Taiwan.

Received: 28 September 2016 Accepted: 14 November 2017 Published online: 21 November 2017

\section{References}

1. Health Promotion Administration, Ministry of Health and Welfare, R.O.C. Annual report of health promotion administration: promoting your health. Taipei City: Health Promotion Administration, Ministry of Health and Welfare, R.O.C; 2015. p. 2015.

2. World Health Organization. Obesity and overweight. In: Media Centre. 2016. http://www.who.int/mediacentre/factsheets/fs311/en/. Acessed 1 June 2017.

3. Hall KD, Sacks G, Chandramohan D, Chow CC, Wang YC, Gortmaker SL, et al. Quantification of the effect of energy imbalance on bodyweight. Lancet. 2011;378:826-37

4. Paradis AM, Godin G, Perusse L, Vohl MC. Associations between dietary patterns and obesity phenotypes. Int J Obes. 2009:33:1419-26.

5. Schulze MB, Fung TT, Manson JE, Willett WC, Dietary HFB. Patterns and changes in body weight in women. Obesity (Silver Spring). 2006;14:1444-53.

6. Ritzer G. McDonaldization: the reader. Thousand Oaks: SAGE Publications; 2009

7. Peng CJ, Lin CY, Guo HR. A comparison of food supply from 1984 to 2009 and degree of dietary westernization in Taiwan with Asian countries and world continents. Biomed Res Int. 2015;2015:628586. doi:10.1155/2015/628586.

8. Center for Nutrition Policy and Promotion. A series of systematic reviews on the relationship between dietary patterns and health outcomes. Alexandria: Department of Agriculture; 2014.

9. Okubo H, Sasaki S, Murakami K, Kim MK, Takahashi Y, Hosoi Y, et al. Three major dietary patterns are all independently related to the risk of obesity among 3760 Japanese women aged 18-20 years. Int J Obes. 2008;32:541-9. doi:10.1038/sj.ijo.0803737

10. Cai H, Zheng W, Xiang YB, WH X, Yang G, Li H, et al. Dietary patterns and their correlates among middle-aged and elderly Chinese men: a report from the shanghai Men's health study. Br J Nutr. 2007;98:1006-13. doi:10.1017/ S0007114507750900.

11. Shi Z, Hu X, Yuan B, Hu G, Pan X, Dai Y, et al. Vegetable-rich food pattern is related to obesity in China. Int J Obes. 2008;32:975-84. doi:10.1038/ijo.2008.21.

12. Wang Z, Zhang B, Zhai F, Wang H, Zhang J, Du W, et al. Fatty and lean red meat consumption in China: differential association with Chinese abdominal obesity. Nutr Metab Cardiovasc Dis. 2014;24:869-76. doi:10.1016/j.numecd. 2014.03.002

13. Xu F, Yin X, Tong S. Association between excess bodyweight and intake of red meat and vegetables among urban and rural adult Chinese in Nanjing, China. Asia Pac J Public Health. 2007;19:3-9.

14. Wang Z, Zhang B, Wang H, Zhang J, Du W, Su C, et al. Study on the multilevel and longitudinal association between red meat consumption and changes in body mass index, body weight and risk of incident overweight among Chinese adults. Zhonghua Liu Xing Bing Xue Za Zhi. 2013;34:661-7.

15. Kimokoti RW, Gona P, Zhu L, Newby PK, Millen BE, Brown LS, et al. Dietary patterns of women are associated with incident abdominal obesity but not metabolic syndrome. J Nutr. 2012;142:1720-7.

16. Cho YA, Shin A, Kim J. Dietary patterns are associated with body mass index in a Korean population. J Am Diet Assoc. 2011;111:1182-6. doi:10.1016/j. jada.2011.05.003.

17. Shi Z, Yuan B, Hu G, Dai Y, Zuo H, Holmboe-Ottesen G. Dietary pattern and weight change in a 5-year follow-up among Chinese adults: results from the Jiangsu nutrition study. Br J Nutr. 2011;105:1047-54. doi:10.1017/ S0007114510004630

18. Chiu YF, Hsu CC, Chiu TH, Lee CY, Liu TT, Tsao CK, et al. Cross-sectional and longitudinal comparisons of metabolic profiles between vegetarian and non-vegetarian subjects: a matched cohort study. Br J Nutr. 2015;114:1313-20. doi:10.1017/S0007114515002937.

19. Department of Health. Identification, evaluation, and treatment of overweight and obesity in adults in Taiwan. Washington, DC: Department of Health; 2003.

20. MJ Group. MJ Health Screening Center Questionnaire QR-121-1 MJ2011.061104TW. http://www.mjlife.com/index.aspx?lang=eng\&fn=mj. Accessed 7 Dec 2014

21. Lyu LC, Lin CF, Chang FH, Chen HF, Lo CC, Ho HF. Meal distribution, relative validity and reproducibility of a meal-based food frequency questionnaire in Taiwan. Asia Pac J Clin Nutr. 2007;16:766-76.
22. Nettleton JA, Schulze MB, Jiang R, Jenny NS, Burke GL, Jacobs DRJ. A Prioridefined dietary patterns and markers of cardiovascular disease risk in the multi-ethnic study of atherosclerosis (MESA). Am J Clin Nutr. 2008;88:185-94.

23. Meyer KA, Sijtsma FP, Nettleton JA, Steffen LM, Van Horn L, Shikany JM, et al. Dietary patterns are associated with plasma $F(2)$-isoprostanes in an observational cohort study of adults. Free Rad Biol Med. 2013;57:201-9.

24. Lockheart MS, Steffen LM, Rebnord HM, Fimreite RL, Ringstad J, Thelle DS, et al. Dietary patterns, food groups and myocardial infarction: a case-control study. Br J Nutr. 2007:98:380-7.

25. Walker J, Almond P. Interpreting statistical findings: a guide for health professionals and students. Berkshire: McGraw-hill Education; 2010.

26. Dietary HFB. Pattern analysis: a new direction in nutritional epidemiology. Curr Opin Lipidol. 2002;13:3-9.

27. Kant AK. Dietary patterns and health outcomes. J Am Diet Assoc. 2004;104: 615-35. doi:10.1016/j.jada.2004.01.010

28. FB H, Rimm EB, Stampfer MJ, Ascherio A, Spiegelman D, Willett WC. Prospective study of major dietary patterns and risk of coronary heart disease in men. Am J Clin Nutr. 2000;72:912-21.

29. Kant AK. Indexes of overall diet quality: a review. J Am Diet Assoc. 1996;96: 785-91. doi:10.1016/s0002-8223(96)00217-9.

30. Warrell DA, Cox TM, Firth JD. Oxford textbook of medicine. New York: Oxford University Press; 2010.

31. Campbell TC, Campbell TM. The China study: the most comprehensive study of nutrition ever conducted and the startling implications for diet, weight loss and long-term health. Dallas: BenBella Books, Inc:; 2005.

32. Drogan D, Hoffmann $K$, Schulz M, Bergmann MM, Boeing $H$, Weikert CA. Food pattern predicting prospective weight change is associated with risk of fatal but not with nonfatal cardiovascular disease. J Nutr. 2007:137:1961-7.

33. Ledikwe JH, Smiciklas-Wright H, Mitchell DC, Miller CK, Jensen GL. Dietary patterns of rural older adults are associated with weight and nutritional status. J Am Geriatr Soc. 2004;52:589-95. doi:10.1111/j.1532-5415.2004.52167.x.

34. Vergnaud AC, Norat T, Romaguera D, Mouw T, May AM, Travier N, et al. Meat consumption and prospective weight change in participants of the EPIC-PANACEA study. Am J Clin Nutr. 2010;92:398-407. doi:10.3945/ajcn. 2009.28713.

35. Miller WC. Diet composition, energy intake, and nutritional status in relation to obesity in men and women. Med Sci Sports Exerc. 1991:23:280-4.

36. Karl JP, Roberts SB. Energy density, energy intake, and body weight regulation in adults. Adv Nutr. 2014:5:835-50.

37. Hill JO, Wyatt HR, Peters JC. Energy balance and obesity. Circulation. 2012; 126:126-32.

38. WHO Expert Consultation. Appropriate body-mass index for Asian populations and its implications for policy and intervention strategies. Lancet. 2004:363:157-63. doi:10.1016/S0140-6736(03)15268-3.

\section{Submit your next manuscript to BioMed Central and we will help you at every step:}

- We accept pre-submission inquiries

- Our selector tool helps you to find the most relevant journal

- We provide round the clock customer support

- Convenient online submission

- Thorough peer review

- Inclusion in PubMed and all major indexing services

- Maximum visibility for your research

Submit your manuscript at www.biomedcentral.com/submit 